The 16th Economic International Conference New Challenges and Opportunities for the Economy 4.0, May 7-8th, 2020, Suceava, Romania

\title{
Organizational Change and Resistence to Change within Companies
}

\author{
Elena Loredana COMĂNESCU
}

https://doi.org/10.18662/lumproc/ncoe4.0.2020/25

How to cite: Comănescu, E.L. (2020). Organizational Change and Resistence to Change within Companies. In C. Nastase (vol. ed.), Lumen Proceedings: Vol. 13. 16th Economic International Conference NCOE 4.0 2020 (pp. 286-298). Iasi, Romania: LUMEN Publishing House. https://doi.org/10.18662/lumproc/ncoe4.0.2020/25 


\title{
Organizational Change and Resistence to Change within Companies
}

\author{
Elena Loredana COMĂNESCU ${ }^{1}$
}

\begin{abstract}
If the general concept of change is only "a new state of affairs different from the old state of things", it is more difficult to define organizational change. The name of organizational change makes it obvious that it is a change in organizational activities, but this statement does not say too much about the type of activities that are subject to change. Making a comparison between operational and organizational change, we will see that the first refers exclusively to individuals, with their roles and values, while the second covers a much broader field, namely all operational processes those of service delivery, customer service, production and logistics. Besides these, organizational change also covers changes that occur in work processes (which can be understood as "a set of work tasks to achieve a clear goal" [1]) and their subsystems. Organizational change can be also defined as "a transitional state between the present state and a future state to which the organization tends" [2]. Another relevant factor in defining change is represented by the causes that determine the apparition of change, which mainly characterizes the radical and paradigmatic change named "second order change" by Levy [17].
\end{abstract}

Keywords: organizational change; resistance to change; motivation and communication in organizations; leadership.

\footnotetext{
${ }^{1}$ Valahia University of Targoviste, Romania. 


\section{Introduction}

Mihail Dumitrescu (1995) [3], in the paper "Introduction to management and general management", considered that “... change generally represents a modification, a transformation or an adjustment in the form and / or content of an object, activity or natural product, of thinking or social."

Gary Johns (1998) [4], in his book "Organizational Behavior", argues that change occurs when a program or plan is implemented to move the organization and / or its members to a more fulfilling state.

In the paper "Organizational progress - change, transformation and organizational innovation" (1999), Ioan Petrişor [5] stated that "change means the attempt of the enterprise to be different. This represents the state of what is changing, evolving."

Organizational change can be easily compared to innovation or even considered innovation. Innovation can be defined as technology, product or practice "used for the first time by the members of an organization, regardless of the fact that it has already been used in other organizations [6]", in other words, the use of an innovation is an innovation itself. Regardless of the truthfulness of this idea, it applies equally to organizational change. From this point of view, change can be understood as well as a continuous process of preparing the organization for the new system and introducing it in such a way as to ensure its success.

As it can be seen above, the ultimate goal of organizational change is success, that is, a better match between the organization and the environment in which it evolves, as well as a more efficient and effective way of working. The success of a change can also be defined as the degree to which the change meets the following criteria:

a. It fulfills the purpose for which it was implemented;

b. It does not exceed the deadline nor the budget that was set to it;

c. It leads to positive economic and operational results in a reasonable period of time, exceeding the costs caused by its implementation;

d. It is perceived as a success by both internal and external members of the organization.

We can therefore conclude that the success of organizational change depends both on the quality of the solution found and on the effectiveness of its implementation, which can have three consequences:

(1) Efficient implementation, the use of innovation or change (interchangeable in the given context) improves the performance of the organization; 
(2) Efficient implementation, but the performance of the organization is not affected in any way;

(3) The implementation is not successful [7].

Organizational change must, therefore, promote a strategy for the evolution of the organization, which obviously cannot be constant, but dynamic.

There are several ways to look at the issue of change in an organization from a practical point of view. What is specific to any organization is the precarious balance, the continuous appearance of tensions, problems. Problems arise, of course, at every level of the organization, within each sub-system that composes the entire organization.

\section{Types of organizational change}

Organizational change can be classified in several categories. The most extensive of these is the one that presents the change according to three major dimensions: the origin, the result and the process of change.

The origin of change has to do with how change occurs within an organization, from the environment in which the organization operates or at the initiative of the latter. Thus, one can speak of unintended changes, which simply happen, and intended or deliberate changes, the actions taken by the organization. Of course, in real life the difference is not so clearly drawn, even the intended changes can be influenced by an event which happens outside the company. Another type of classification can be made depending on how the change is linked to external events, reactive changes (changes due to an event or series of events) and anticipatory changes (changes due to as anticipation of events) [8].

The most common classification of organizational changes is based on the amplitude of radical change. The concept of "radical change" and other close ones are presented in the table no. 1.

Table no. 1. Types of organizational changes

\begin{tabular}{|l|l|l|}
\hline & \multicolumn{1}{|c|}{ Classification } & \multicolumn{1}{c|}{ Essential difference } \\
\hline Gersick, 1991 & $\bullet$ Gradual change & $\begin{array}{l}\text { Supports the basic } \\
\text { structure }\end{array}$ \\
& $\bullet$ Revolutionary change & $\begin{array}{l}\text { Replaces the existing } \\
\text { structure and order }\end{array}$ \\
\hline $\begin{array}{l}\text { Dunphy şi Stace, } \\
1988\end{array}$ & $\begin{array}{l}\text { Incremental change } \\
\text { Transformational change }\end{array}$ & $\begin{array}{l}\text { Continuous, on a low } \\
\text { scale }\end{array}$ \\
& $\begin{array}{l}\text { No continuity, on a high } \\
\text { scale }\end{array}$ \\
\hline
\end{tabular}




\begin{tabular}{|c|c|c|}
\hline Levy, 1986 & $\begin{array}{l}\text { - } 1^{\text {st }} \text { degree change } \\
\text { - } 2^{\text {nd }} \text { degree change }\end{array}$ & $\begin{array}{l}\text { - Change in the basic rules } \\
\text { of the system } \\
\text { - Exemplary change that } \\
\text { modifies the } \\
\text { metaregulations of the } \\
\text { system }\end{array}$ \\
\hline $\begin{array}{l}\text { Tushman et al., } \\
1986\end{array}$ & $\begin{array}{l}\text { - Grouped change } \\
\text { - Transformational change } \\
\text { that modifies the frame }\end{array}$ & $\begin{array}{l}\text { - Compatible with the } \\
\text { existing organizational } \\
\text { structure } \\
\text { - At the system level, } \\
\text { competing change in } \\
\text { strategy, power, structure } \\
\text { and control }\end{array}$ \\
\hline $\begin{array}{l}\text { Fiol şi Lyles, } \\
\text { 1985- } \\
\text { organizational } \\
\text { learning }\end{array}$ & $\begin{array}{l}\text { - Low level of learning } \\
\text { - High level of learning }\end{array}$ & $\begin{array}{l}\text { - Behavioral change, within } \\
\text { the organizational } \\
\text { structure } \\
\text { - Cognitive change }\end{array}$ \\
\hline $\begin{array}{l}\text { Miller \& Friesen, } \\
1984\end{array}$ & $\begin{array}{l}\text { - Evolutionary } \\
\text { - Revolutionary }\end{array}$ & $\begin{array}{l}\text { - Few changes } \\
\text { - Large number of changes }\end{array}$ \\
\hline $\begin{array}{l}\text { Greiner, 1972- the } \\
\text { lifetime of the } \\
\text { organization }\end{array}$ & $\begin{array}{l}\text { - Evolution } \\
\text { - Revolution }\end{array}$ & $\begin{array}{l}\text { - Uses the dominant type } \\
\text { of management to achieve } \\
\text { a constant growth } \\
\text { - A new management type } \\
\text { for further growth }\end{array}$ \\
\hline
\end{tabular}

Source: Dunphy and Stace, 1988; Nadler and Tushman, 1989; Gersick, 1991 [9], [8], $[10]$.

As it is shown in the table, not all authors understand the essential difference between the types of change. Below we will present an organization model and its subsystems that can be alternated so that they change simultaneously or the change affects only one of them, with little effect on the others.

Some authors make a distinction between radical and gradual change as evolution types[10], but others consider evolutionary change being the opposite of radical change [9], [18]. Another author [11] proposes another type of change - the "tectonic change", because, he says, "the two existing types rarely adapt only to the real context of change". The tectonic change is caused by an important difference between existing and ideal organizations, which highlights the need for change, but does not cause as much stress as other types of change. This type of change is interesting and useful because, 
despite the existence of many models, there is no clear theoretical distinction between the "classical" types of change.

A classification from a managerial point of view can be made as the level of change the extent to which the organization is affected by change. An example of a change at the low level would be the reorganization of the structure of the jobs, while a change at the level of the entire organization would be its complete restructuring. Stace and Dunphy (1994) [9] states, giving precise examples of interventions at each level:

(1) Macrointervention which affects the whole company - strategic analysis, existence of a vision or a development mission, strategic establishment of positions, restructuring and reorganization the whole work process at one specific level of organization.

(2) Major intervention which affects a production unit - formation of a unit, strategic planning or positioning, continuous improvement programs, recruitment of new management.

(3) Intergroup intervention - strategies for training intergroup teams, restructuring work teams and reorganizing the whole process of working.

(4) Staff intervention - staff development, professional development, job reorganization and leadership development.

The process of change is the dimension according to which the organizational change can be classified and refers to the modalities and progression of events in the change of the company. The change process can be classified according to its duration and the resources (human or material) used to implement the change [21]. The unity of change can be a singular entity - an individual or an organization - or the interaction between people or relationships within a company. The modality of change describes what exactly determines the sequence of events or whether it is constructed by the changing entity as the process evolves [12].

The most common classification of organizational change by process is that which refers to two main change processes - planned change and accidental or emergent change [22], [24]. The two types are distinct, respectively the planned change is formal, and the accidental one is informal, the first is imposed within the organization and the second has its origin outside.

Planned change is a proactive change that the employees of a company deliberately initiate and implement in order to anticipate or respond to changes in the environment or to pursue new opportunities.

The purpose of the planned change is to anticipate events and look for ways to improve the situation [13]. A feature without which this fact 
could not occur is the ability to see as a whole, as well as to have a clear concept of the future state that is pursued through change.

One of the fundamental elements of the planned change is the importance of the management and, in particular, of its top echelons; the change has its origin in their initiatives. In addition to initiating change, management is actively involved in its planning and implementation, so that the entire process is centralized.

The central element of the planned change is suggested by name the planning of the change. The process is sequential; the implementation takes place after the strategy has been defined [20]. From this point of view, the planned change occurs through a process of efficient managed events, constantly supervised. Thus, there is a clear implication that the condition to be accomplished and the ways in which this happens are clearly formulated and can be implemented as a final conception.

Accidental or emergent change is the opposite of planned change, but it does not have its spread and use. The change bappens from the permanent activity of the members of the organization, as they respond to problems and opportunities. The change is imposed by outside, the management creates potential of change, and the employees carry out the implementation, which is made incrementally by several changes at the lower level which will lead to a major organizational transformation.

Organizational changes are, for the most part, planned, intended changes, introduced by management for different reasons. Organizational changes are more observed in a orderly and better structured space than social changes. Also, the changes that take place at the organizational level are often carried out in a shorter period of time than those at the macro level. Another difference is the identification of the agent of change because of the characteristics mentioned so far, it (or they) can be identified with relative ease. Another difference is that, in the case of organizational changes, the systemic paradigm holds the supremacy; example the most used way in the organizational development to measure the effects of a change: a set of characteristic elements of the system is measured before and after the change, the variation representing the effect of the intervention. In other words, two different stages of the system are measured, appreciating the inequalities between them at different times of time - exactly the basic principles of the systemic model.

The theoretical space of organizational change has several characteristics, which are related to metal packaging; Most of the specialized literature is written from a managerial point of view, which is obviously interested in the most efficient ways in which it could introduce change in the company it manages. Another characteristic regards the fact that there 
are two major types of approaches to the problem of organizational change: those that are explanations of how to implement a planned change and those that are process descriptions, which analyze the change and do not provide norms for its implementation. practice.

The multiple aspects of organizational change were widely presented by Milan Kubr (1992) [14] in the "Management Consultant's Handbook". These would be:

- changes in the way of setting up organizations (legal status, form of ownership, field of activity, etc.);

- changes in tasks and activities (the list of products or services offered, suppliers, customers and markets);

- changes in the technology used (equipment, technological processes, tools, materials and energy);

- changes in management structures and processes (company chart, decision-making process, information system, internal control procedures);

- changes in the organizational structure (leadership style, influences, values and traditions);

- changes among the people (the management team, the execution personnel, the competence, the motivations, the behavior and the efficiency in the work);

- changes in the organizational performance (economic, financial, social, the way in which the organization integrates into the activity environment and fulfills its mission);

- changes of the image created by the organization in business circles and in society.

Linda Ackerman (1986) [23] has presented, in the work "Development, transition or transformation: the problem of change in the organization", three main types of organizational change:

- change of development which consists in improving the skills, methods or conditions which for certain reasons cannot meet the current expectations;

- transitional change which means the implementation of a new known state (reorganization, the introduction of new services, products and technologies, processes and systems). Transitional changes may involve developmental changes;

- transformational change that implies the implementation of a new unknown state, being the result of a succession of transitional changes. This involves going through some developmental changes as well as some transitional changes. 


\section{Resistence to change in the organizational space}

In general, this appearance is described as irrational, counterproductive behavior of a minority within the organization, with negative consequences on the whole system. So, resistance to change is a bad thing. Is this really the case? How do we appreciate the attitude of some doctors who do not agree the change of hospital practice on the grounds that the care of the patients would suffer? Or the refusal of the operators of a nuclear power plant to accept personnel reductions because it would affect the security of the operation of that plant?

Giving a value to resistance to change depends largely on the point of view from which the situation is evaluated. It is very probably that a certain behaviour is seen by some members of the organization as extremely harmful, even destructive, while for others it is something of great esteem.

Most of the theories about resistance to change has been defined from the point of view of management and are focused on the methods by which resistance can be exceed, implementing change, fast and efficiently. It is clear that in such approach, resistance to change is considered as a negative thing, which must be defeated, for the future good of the company.

Since 1940 and up to now, a lot of studies and articles have been published advising managers how to exceed resistance to change in their own company.

Of these, the theory of Coch and French has its beginning in a famous study in the specialized literature, the first research that systematically addressed the problem of efficiency from the perspective of resistance to change [19]. This is the study of Harwood Manufacturing Corporation, a textile company, started in 1948. The organization was headquartered in Marion, Virginia and had 600 employees, of which 100 were men. Most of the employees were from rural areas, with no experience in industrial activity. The average level of education was around the eighth grade and the average age 23 years. During the period immediately preceding this study, the respective company had undergone a set of changes, introduced by the management, in order to maintain the organization's competitiveness in the market, to increase its efficiency. Mainly, it was about introducing a new technology and a new division of the production activity. The problem faced by Harwood Corporation was an obvious resistance of the employees to recent changes, expressed by a low efficiency, an aggressive attitude towards the management, a high rate of fluctuation of the personnel, evident bad-will in fulfilling the different obligations of service.

The problems were all the more astonishing as the organization practiced liberal management, paying close attention to human resource 
management problems. The remuneration were satisfactory (there were two types of minimum salaries, one for new workers and another, $22 \%$ higher, for workers with 6-month experience), the targets were high but not impossible to meet (the average norm was 60 units of product per hour; on average 34 weeks were required to reach the skill level that allowed for a full norm) and were worked individually. To raise morale and enhance competitiveness among workers, lists of daily performances were displayed daily, the focus being on those who succeeded in meeting or exceeding the norm.

Major problems began to emerge with the introduction of new technologies, which made it necessary to transfer certain workers from one area of activity to another. Initially, it was considered that the resistance to change was caused by the fact that the workers could not be comfortable with the new jobs and they rejected the management interventions. This rule was also sustained by the fact that only $38 \%$ of those transferred managed to return to the norm of 60 units per hour.

The authors of the study considered, however, that resistance to change is a more complex force and that it does not depend only on the change of the work place, especially since those who managed to return to the "normal" level of productivity exhibited behaviors, rejection of management initiatives. Moreover, these attitudes were also present among those who had not been transferred. As a result, several hypotheses have been formulated: (1) there is a motivating force that pushes the workers to reach the minimum level of 60 units per hour or more; the force increases as the worhers approaches their purpose; (2) there is a resistance force, contrary (1), which stops the high productivity and increases with its level and (3) the frustration force generated by the conflict between (1) and (2) is a function of the weakest of the respective forces, as long as this force is much more important than the minimum level required to produce the phenomenon of frustration.

Coch and French started from the hypothesis that, within the "negative" or "disruptive" resistance, dynamics and norms of groups have the same importance as the individual characteristics. In order to check it out this hypothesis, the researchers have been a lot of meetings with some of the workgroups in the factory, in their contents explaining to the workers why the changes that were so disturbing were introduced and why their coparticipation is needed. to the management's effort to increase the efficiency of the company. The other groups were told nothing. Coch and French found that, in the case of those groups that were offered explanations about the changes that occurred, resistance decreased significantly, while the attitude of the rest of the employees remained unchanged. Thus, the authors 
could affirm that the explanation of the management measures and the coparticipation of the workers in their implementation are of high importance in reducing the "disruptive" resistance to change. Resistance to change is a combination of individual reactions to frustration and strong group strengths.

This study was among the first to draw attention to group methods of exceeding resistance to change and had a great influence on persuading managers to use group participation methods in their attempts to introduce change in companies.

Another important theory about "how to overcome resistance to change" is "field theory", better known as "force field analysis", created by one of the greatest analysts in the field of sociology and organizational psychology, Kurt Lewin [15].

Lewin describes organizations as systems in a stable state, of balance between equal forces and the opposite direction. There are the "pro-change" forces, such as the pressure of competition, new technology, innovation and creativity within the company, new laws in the economic field, environmental protection or legislation regarding the work and rights of individuals in this context, etc. Counterbalancing these forces is what Lewin calls "resistance forces", which include the customs, tradition of the organization, treaties concluded in the past with unions, culture and organizational climate, etc. The two sets of forces have the same intensity and cancel each other, so that the organizational system is maintained in a stable equilibrium. The consequence of this model is that if we want to introduce a change, we must destabilize the balance of these forces, strengthen, increase the "pro-change" forces to annihilate the "resistance forces". Once this is achieved, a new equilibrium position is reached, which includes the situation, the elements that we wanted to introduce into the company through the change that took place. It is, therefore, a temporary break in the balance of forces, a pressure that ceases when the desired state has been achived.

Lewin considered that there are three stages in implementing a change - the unfreezing phase, the change phase and the final stage of refreezing. In order to unfreeze an organization, a careful evaluation of the forces of "resistance" is needed; any multilateral, premature increase of forces favorable to change will automatically lead to increased opposition to change. Therefore, in order to minimize the "resistance" forces, the management should consult the groups of workers aimed at change in order to obtain their co-participation. After this stage, the change could be implemented and the equilibrium position changed to the desired state. The third phase of the process is very important for fixing the newly introduced 
change, for its inclusion in the daily routine of the organization. Within the refreezing stage, a number of techniques and strategies are used, such as rewarding the desirable behaviors of workers and developing new sets of rules to help integrate the new situation into the ordinary life of organizations.

The main quality of K. Lewin's model is that it offers an easy way to understand the force game when introducing a planned change in a company. He said that, regardless of the type or amplitude of the change, there will be opposing forces that must be taken into account by managers initiating change. But this model does not say anything about the reasons that cause the different groups to resist change and only offers a very general view for approaching organizational change.

Paul Lawrence published an article in Harvard Business Review that made the distinction between the resistance generated by the technical and social aspects of change [16]. In the first case, the structure of the social interaction between the workers was not affected at all - the resistance was extremely low; In the second case, the introduction of an assembly line - the resistance to change was extremely high. Lawrence's conclusion: resistance to change is directly proportional to the degree to which the model is affected, the set of social relations in the respective company. This assertion applies not only to the lower levels of the organizational hierarchy but also to the top management ${ }^{2}$.

In conclusion, it can be stated that organizational change represents the process by which an organization adapts to the environmental demands in which it operates, by partially or completely transforming the internal processes and the resources available or attracted, based on the anticipation of future reactions and management. legal and efficient potential risks associated with the activity environment.

With regard to the concept of resistance to change, this is not an essentially negative phenomenon as the managerial inspiration literature implies, and it is influenced by a complex of factors that can be structured into two broad categories: the "causes" of resistance to change (the factors that determine the individual, group and organizational levels) and the type of change that produce it.

\footnotetext{
${ }^{2}$ Let us consider the reluctance with the introduction of modern means of communication in many organizations has been met; Besides the fear that, having a more flexible communication network, they will lose one of the control levers they had mastered until then, many managers were upset by the way the new technology affects the interaction with their colleagues: fewer direct contacts, more information autonomy, etc.
} 


\section{Acknowledgment}

This work is supported by project POCU 125040, entitled "Development of the tertiary university education to support the economic growth - PROGRESSIO", co-financed by the European Social Fund under the Human Capital Operational Program 2014-2020

\section{References}

[1]. Davenport TH, Short JE. The New Industrial Engineering: Information Technology and Business Process Redesign. Sloan Management Review; 1990.

[2]. Huse EF, Cummings TG. Organization Development and Change. West Publishing Company; 1985.

[3]. Dumitrescu M. Introducere în management şi management general. Oradea: Ed. Eurounion S.R.L.;1995.

[4]. Johns G. Comportament organizațional. Ed. Economică; 1998.

[5]. Petrişor I. Progresul organizațional - schimbare, transformare şi inovare organizațională“, Ed. Mirton; 1999.

[6]. Nord WR, Tucker S. Implementing routine and radical innovations”. Lexington Books; 1987.

[7]. Klein KJ, Sorra JS. The challenge of innovation implementation. Academy of Management Review; 1996.

[8]. Nadler DA, Tushman ML. Organizational Frame Bending: Principles for Managing Reorientation. The Academy of Management Executive; 1989.

[9]. Dunphy DC, Stace DA. Transformational and coercive strategies for planned organizational change: beyond the O.D. model. Organization Studies; 1988.

[10].Gersick CJ. Revolutionary Change Theories: A Multilevel Exploration of the Punctuated Equilibrium Paradigm. Academy of Management Review; 1991.

[11]. Reger RK, Gustafson LT, Demarie SM, Mullane JV. Reframing the organization: Why implementing total quality is easier said than done. Academy of Management Review; 1994.

[12]. Van de Ven AH, Marshall Scott Poole MS. Explaining Development and Change in Organizations. The Academy of Management Review. 1995; 20 (3):

[13]. French WL, Bell C. Organization Development: Behavioral Science Interventions for Organization Improvement. Prentice Hall; 1999.

[14]. Kubr M. Manualul consultantului în management. Ed. Amcor; 1992.

[15]. Lewin K. Field Theory in Social Change. New York: Harper \& Row; 1951.

[16]. Lawrence P. How to Deal with Resistance to Change. Harvard Business Review; January-February 1969.

[17]. Levy A, Merry U. Organizational transformation - approaches, strategies, theories. New York: Praeger Publishers; 1986.

[18]. Pettigrew A. The Awakening Giant. Continuity and Change in ICI. Oxford: Basil Blackwell; 1985. 
[19]. Coch L, French JRP. Overcoming Resistance to change. Human Relations; 1948, 2.

[20]. Mintzberg H. Strategy Formation: Schools of Thought. New York: Ed. Perspectives on Strategic Management, Harper Business; 1990.

[21]. Salminen A. Implementing Organizational and Operational Change. Helsinki: Finnish Academy of Technology; 2000.

[22] Macredie RD, Sandom C. Article Modelling for Change: An Information Systems Perspective on Change Management Models In: Macredie R., Paul R., Anketell D., Lehaney B., Warwick S. (eds). Modelling for Added Value. Springer, London; 1998.

[23] Ackerman LS. Beyond Change Management. Jossey-Bass; 1986.

[24] Farrell M. Developing a Market-Oriented Learning Organisation. Australian Journal of Management. 2000; 25(2). 